\title{
Towards human-computer interaction on smart metering systems
}

\author{
Juan C. Olivares-Rojas, Enrique Reyes-Archundia, José A. Gutiérrez- \\ Gnecchi, Ismael Molina-Moreno, J. Guadalupe Ramos-Díaz, and J. Gabriel \\ González-Serna
}

Published: 30 November 2020

\begin{abstract}
New technologies associated with the fourth industrial revolution are transforming the world in which we live, and the power grid is no exception since it has been provided with intelligence. One of its best-known applications is smart metering systems that allow real-time energy consumption/production to be known, as well as other benefits such as outages and reconnections automatically. The new generations of smart meters have more computing capacity allowing new applications. This work shows some considerations in the design of smart meters using human-computer interaction techniques. The results aim to improve the end-user's experience and satisfaction and can help to mitigate the reluctance to use smart metering systems in Mexico.
\end{abstract}

\section{Keywords}

AMI; HCI; Smart Meters.

\section{Introduction}

With the arrival of the new technologies of the fourth industrial revolution, many human processes have been benefited in the way of improving the quality of life. One of the most benefited processes is the electricity sector, allowing a reliable, quality, environmentally friendly, and cost-effective supply of electrical energy [10]. One of the most visible parts of the Smart Grid (SG) is the Smart Metering System (SMS) that allow the monitoring of the consumption and production of electrical energy by prosumers at all times and automatically, reducing costs in the medium and long term. One of the essential SMS architectures is the Advanced Measurement Infrastructure (AMI) [17], which is based on the use of smart meters and other components that allow two-way communication and data processing [7].

Currently, all systems must be understood as cyber-physical systems (CPS) since they are a combination of objects, people, processes, and data. Thus, SMS can be considered as a CPS [16].

Olivares-Rojas, JC., Reyes-Archundia, E., Gutiérrez-Gnecchi, JA., Molina-Moreno, I., Ramos-Díaz, JG.

Tecnológico Nacional de México / Instituto Tecnológico de Morelia juan.or@morelia.tecnm.mx, enrique.ra@morelia.tecnm.mx, jose.gg3@morelia.tecnm.mx, ismael.mm@morelia.tecnm.mx, j.rd@morelia.tecnm.mx

González-Serna, JG.

Tecnológico Nacional de México / CENIDET

gabriel.gs@cenidet.tecnm.mx
People are crucial in any system. In addition, the human factor is essential in the proper functioning of any order. HumanComputer Interaction (HCI) aims to improve how people relate to the hardware and software elements of cyber-physical objects in our environment through data and processes [5].

SMS are made up of:

- Objects: smart meter, data concentrators, measurement database servers, wireless and wired links, telecommunications equipment, among others.

- People: consumers, small producers, prosumers, lecturers, technical operators of distribution and transmission lines, managers of telecommunications networks, operators of computer systems and databases, among others.

- Processes: Measurement of consumption readings and production of electrical energy, data communication, data storage, consumption patterns, billing, statistical reports, among others.

- Data: consumption, production, variables of the electrical signal, energy prices, dates, state of the electrical and telecommunications network, customer data, among others.

Figure 1 shows the SMS considered as a CPS.

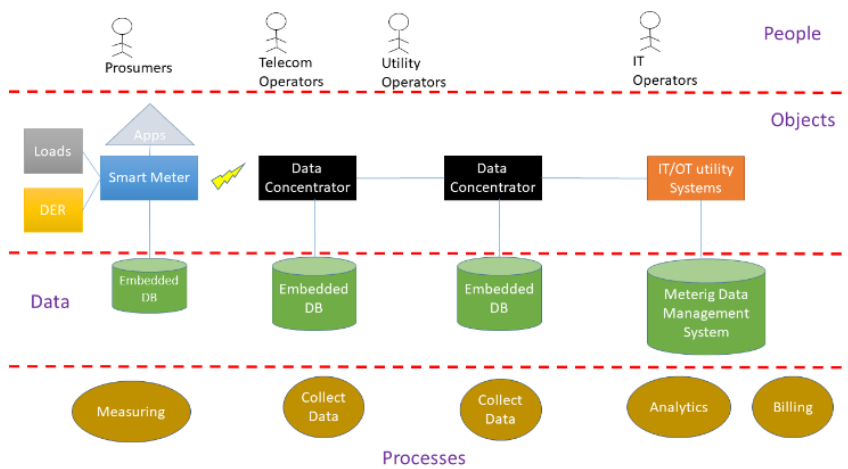

Figure 1 Smart Metering Systems as a CPS.

Despite the enormous advantages of SMS, its use has little spread in developing countries. This is mainly due to the misinformation of their service and, above all, to the erroneous belief that these systems can be dangerous to health or have excessive monitoring of privacy in the homes of users due to the identification of consumption patterns.

Although the use of SMS dates from 2007, it is until 2014 that these have been introduced in Mexico. They were originally placed in low-income neighborhoods but due to consumer reluctance to let 
them install, they have moved to install in upper-middle-income neighborhoods such as gated communities where readers cannot easily get through and where it exists robust communications infrastructure.

We believe that the proper use of HCI elements can be a key element in the successful introduction of SMS in Mexico and in other countries. However, in recent years, various studies related to HCI have been carried out in multiple areas of SG [31], but few in SMS [14], being a relevant factor in the lack of confidence of endusers in many countries [21].

This work shows a comparative study of various related researches in the field of HCI for SMS, showing its main characteristics. The results found are discussed in section 3, proposing some guidelines to improve the usability of SMS on the way to improving its acceptance in the Mexican electricity market.

\section{State of the art}

Following, the description of the main works related to the $\mathrm{HCI}$ area in SMS are presented.

One of the most relevant aspects for end-users is knowing their consumption of electrical energy that allows them to save money by making better use of their electrical appliances. In general, SMS has a web or mobile application to show the information to customers; some countries have installed specialized devices called home-displays to provide information. However, such interaction is more informative than interactive. In [18], work is shown where the interaction between users and the public service company is achieved through mobile devices, giving feedback to both the users and the electricity company that translate into cost savings and service improvements. In [4] is reported the design of an SMS application focused on mobile apps.

Social interaction is highly relevant in practically any cyberphysical system; for this reason, some research has focused on managing social media to achieve greater interaction by users. For example, [22] shows the combination of social networks with SMS to improve the display and persuasion of users.

One of the most relevant concerns of SMS clients is the cybersecurity and privacy of their information [9] [15]. Therefore, today, any SMS system must consider the cybersecurity and privacy as a fundamental part of its interaction with users.

Not all innovation can be considered successful when end users interact with it. In [11], a study is shown of how the non-use of the services that provide SMS can be successful in countries like Finland. In [32], a study is shown with the main concerns of users who use SMS. In turn, [28] shows a study on visions on the energy issue for smart homes that share the same concept with SMS.

In general, there are various studies of HCI that can be applied in the context of SMS. For example, in [20], general guidelines for creating smart environments are shown, which can be easily adapted to SMS environments.

On the other hand, some works have focused on the analysis of data patterns through various statistical and machine learning techniques to show the consumption behavior of users. For example, in [3], work is shown to extract, visualize, and interpret the consumption data of residential customers; however, the HCI is little considered. In [24], a study of information services based on energy consumption for inhabitants of a smart home is shown.

Currently, with the integration and lowering of energy generation systems by renewable sources such as photovoltaic panels and wind turbines, it has become possible for end-users to produce their energy and sell the surplus to the electricity company and even to other users. This type of new electrical energy commercialization system has been called transactive systems, which is why some works, such as in [25], have focused on the interaction of various prosumers to exchange their own energy. One of the technologies that have enabled this class of transactional systems is Distributed Ledger Technologies like blockchains.

A novel application of SMS is its integration with Electric and Autonomous Vehicles (EAV). Some works such as [12] have focused on how these vehicles can be integrated into the smart grid through SMS. However, little work has been done in the HCI field in this regard. In [29], schematics of Human-Machine Interfaces (HMI) for EV and its evolution towards Human-Robot Interfaces (HRI) are shown, which may also apply to SMS.

An essential part of innovation within the HCI area is the use of new user interfaces, both hardware and software. For example, [6] shows an ultrasonic touchscreen 3D interface with gesture recognition for use on smart devices. This type of interface could be installed in next-generation SMS. In [2], a review of the various electronic instrumentation components of SG systems, including SMS, is shown. In [30], a study of quality in HMI for embedded systems is shown, which may be applicable in the context of SMS.

Developing software on any cyber-physical system is challenging and SMS is no exception. Various works have focused on this aspect. For example, [26] [1] show various software models focused on SG and within its domains on SMS.

One of the most important aspects of all HCI is the design of hardware interfaces. For this reason, various works such as [27], [23] [13] show the development of smart meters with the design of relevant electrical-electronic components and extremely useful for improving the user experience (UX) in SMS.

Finally, in Mexico, there is a lack of related work in SMS fields, the works are related to other technical aspect such as communications [8] or focused in other electrical appliances like smart thermostats [19]. In this way, it is very crucial a formal study of SMS with HCI to improve the user acceptance of this new devices in Mexico electrical prosumers.

\section{Results and discussion}

From the literature review, the following relevant elements were found in the design, development, and implementation of HCI in SMS.

First, access to the SMS application must be easy through various devices and adapted to the different display and processing capabilities.

Second, electricity consumption and production information should be displayed simply. Data analysis should be performed and displayed graphically. It is imperative that the user can interact with their different high-consumption appliances such as refrigerators, air conditioners, heaters, irons, washing machines, lighting systems, among others. This interaction must clearly show how much energy (and especially money) is consumed when one or other devices are turned on.

Third, aspects of social interaction should be considered, such as showing customers on social networks that billing from one period to another, seeing how that consumption improved as well as the socialization of various aspects of electricity service.

Fourth, cybersecurity and data privacy should be essential, especially if social interaction between different clients is expected. It is important that the readings of both the consumption and production of electrical energy are safeguarded. In turn, it is necessary that said information, if it is shared, have the informed consent of the client, since this information is classified as personal data.

Fifth, for Mexican residential customers, it is essential that SMS interfaces make it possible to know the costs of electricity at 
all times. In Mexico, although there are already some places that have SMS, their use in the country is not widespread, so it will be necessary to have introductory campaign that shows all the possible advantages of these systems since the Mexican user is generally extremely reluctant to install new smart meters.

Sixth, SMS must be easily integrated with various smart home technologies to be able to interact with these devices and, above all, to know their electricity consumption and the costs involved in said consumption.

Seventh, SMS development should include disruptive technologies that, in recent years, have revolutionized our daily lives. Among these technologies are blockchains that allow information to be stored safely. Derived from blockchains, the concept of transactional energy systems emerges, allowing prosumers to market to each other the energy produced from renewable sources using cryptocurrency schemes. For this reason, it is necessary that SMS have a wide variety of payment methods and that they are updated frequently.

Eighth, the SMS must be integrated with the EVs to measure their high consumption of electrical energy and, above all, allow the e-mobility of any electrical charge, particularly those with high consumption and which are easy to move. For example, tomorrow, if a friend wants to connect his EV in our house, this high consumption of electrical energy and, therefore high cost, may be billed and charged to his account of his utility.

Ninth, smart meter hardware development should consider that unlike traditional meters that could last a lifetime, smart meters have a 10-year life span due to rapid hardware obsolescence. For this reason, the meters must continuously update their software. On the other hand, for smart meters to have greater market penetration, they need to have greater functionality. For this, sensors such as temperature, humidity, movement, or even a video camera can be integrated to help new applications such as climate control and video surveillance.

Finally, SMS must be smart enough so that it can be adapted to different types of clients with varying types of roles and characteristics. For this reason, they must have sufficient computing capacity to carry out artificial intelligence processes and the deployment of friendly user interfaces that improve the experience of users in the use of electrical energy in homes, offices, and industry.

\section{Conclusions and further work}

It is imperative to know the characteristics of the users and especially the environment in which they are developed. The fact that SMS is used successfully in other countries does not guarantee that it will be used in the right way in another country or region. For this reason, this work shows a comprehensive study of various investigations in the field of HCI for SMS. It summarizes the main characteristics that must be taken into account in the development of next-generation SMS so that users can best use these systems, and there is little chance of rejection.

The next steps in this research will be focused on the construction of a SM hardware and software using the HCI guidelines founded in this work for the Mexican end-users. The use of this new SM can be reduce the impact on the rejection of the rollout of SMS in the Mexican electric market

\section{Acknowledgments}

The authors would like to thank to Tecnológico Nacional de México for the support grants 7948.20-P and 8000.20-P.

\section{References}

[1] Anvaari, M., et al. (2012). Challenges on software defect analysis in smart grid applications. First International Workshop on Software Engineering Challenges for the Smart Grid. IEEE Press, pp. 19-22.DOI: https://doi.org/10.1109/SE4SG.2012.6225712.

[2] Bhatt, J., et al. An instrumentation engineer's review on smart grid: Critical applications and parameters. Renewable and Sustainable Energy Reviews 40, pp. 1217-1239. DOI: https://doi.org/10.1016/j.rser.2014.07.187.

[3] Borgeson S., et al. (2015). Learning from Hourly Household Energy Consumption: Extracting, Visualizing and Interpreting Household Smart Meter Data. Design, User Experience, and Usability: Interactive Experience Design. Lecture Notes in Computer Science 9188. DOI: http://doi.org/10.1007/978-3-319-20889-3_32.

[4] Böhm, S., and Szwec, L. (2013). Smart Metering with Smartphones: User-Centered Design of a Mobile Application in the Context of Energy Efficiency. Design, User Experience, and Usability. Web, Mobile, and Product Design. Lecture Notes in Computer Science 8015. DOI: http://doi.org/10.1007/978-3-642-39253-5_70.

[5] Culley, K., and Madhavan, P. (2013) Trust in automation and automation designers: Implications for HCI and HMI. Computers in Human Behavior 29:6, pp. 2208-2210. DOI: https://doi.org/10.1016/j.chb.2013.04.032.

[6] Dam, B., et al. (2016) In-Air Ultrasonic 3D-Touchscreen with Gesture Recognition Using Existing Hardware for Smart Devices. 2016 IEEE International Workshop on Signal Processing Systems, Dallas, pp. 74-79. DOI: https://doi.org/10.1109/SiPS.2016.21.

[7] Dileep, G. (2020). A survey on smart grid technologies and applications. Renewable Energy 146, pp. 2589-2625. DOI: https://doi.org/10.1016/j.renene.2019.08.092.

[8] Garcia-Hernandez, J. (2015). Recent Progress in the Implementation of AMI Projects: Standards and Communications Technologies. International Conference on Mechatronics, Electronics and Automotive Engineering (ICMEAE), Prague, pp. 251-256. DOI: 10.1109/ICMEAE.2015.43.

[9] Gunduz, M., and Das, R. (2020) Cyber-security on smart grid: Threats and potential solutions. Computer Networks 169. DOI: https://doi.org/10.1016/j.comnet.2019.107094.

[10] Kabalci, E., and Kabalci, Y. (2019). Chapter 1 - Introduction to smart grid and internet of energy systems, From Smart Grid to Internet of Energy, Academic Press, pp. 1-62, DOI: https://doi.org/10.1016/B978-0-12-819710-3.00001-6.

[11] Kahma, N., and Matschoss, K. (2017). The rejection of innovations? Rethinking technology diffusion and the nonuse of smart energy services in Finland, Energy Research \& Social Science 34, pp. 27-36. DOI: https://doi.org/10.1016/j.erss.2017.05.024.

[12] Kovacs, A., et al. (2015). End-to-End Integration of the V2G Interface with Smart Metering Systems (Results of the EU Co-funded FP7 Project "PowerUp"). Electric Vehicle Systems Architecture and Standardization Needs. Lecture Notes in Mobility. DOI: http://doi.org/10.1007/978-3-31913656-1_9. 
[13] Marimuthu, K., et al. (2018). Development and implementation of advanced metering infrastructure for efficient energy utilization in smart grid environment. Int Trans Electr Energ Syst. 28. DOI: https://doi.org/10.1002/etep.2504.

[14] Martins, J. (2019). Chapter 4 - Smart Meters and Advanced Metering Infrastructure. Pathways to a Smarter Power System, Academic Press, pp. 89-114. DOI: https://doi.org/10.1016/B978-0-08-102592-5.00004-1.

[15] Maziku, H., et al. (2019). Security risk assessment for SDNenabled smart grids. Computer Communications 133, pp. 111. DOI: https://doi.org/10.1016/j.comcom.2018.10.007.7.

[16] Molina, E., and Jacob, E. (2018). Software-defined networking in cyber-physical systems: A survey. Computers \& Electrical Engineering 66, pp. 407-419. DOI: https://doi.org/10.1016/j.compeleceng.2017.05.013.

[17] Montazerolghaem, A., et al. (2018). OpenAMI: SoftwareDefined AMI Load Balancing. IEEE Internet of Things Journal 5:1, pp. 206-218. DOI: https://doi.org/10.1109/JIOT.2017.2778006.

[18] Nguyen, S. (2014). Mobile application for household energy consumption feedback using smart meters: Increasing energy awareness, encouraging energy savings and avoiding energy peaks. 2014 International Conference on Collaboration Technologies and Systems, Minneapolis, pp. 291-296. DOI: https://doi.org/10.1109/CTS.2014.6867579.

[19] Ponce, P., et al. (2019). Usability perceptions and beliefs about smart thermostats by chi-square test, signal detection theory, and fuzzy detection theory in regions of Mexico. Front. Energy 13, pp. 522-538. DOI: https://doi.org/10.1007/s11708-018-0562-2

[20] Pourzolfaghar ,Z., and Helfert, M. (2016). Investigating HCI Challenges for Designing Smart Environments. HCI in Business, Government, and Organizations: Information Systems. Lecture Notes in Computer Science 9752. DOI: http://doi.org/10.1007/978-3-319-39399-5_8.

[21] Raman, S., et al. (2014). A human machine interface (HMI) framework for Smart Grid system. 2014 IEEE Innovative Smart Grid Technologies - Asia, Kuala Lumpur, pp. 318322. DOI: https://doi.org/10.1109/ISGT-Asia.2014.6873810.

[22] Røsok, J. (2014). Combining smart energy meters with social media: Increasing energy awareness using data visualization and persuasive technologies. 2014 International Conference on Collaboration Technologies and Systems, Minneapolis, pp. 27-32. DOI: https://doi.org/10.1109/CTS.2014.6867538.

[23] Sayed, S, et al. (2019). Design and realization of an opensource and modular smart meter. Energy Sci Eng. 7, pp. 1405- 1422. DOI: https://doi.org/10.1002/ese3.361.

[24] Schwanzer, M., and Fensel, A. (2010). Energy Consumption Information Services for Smart Home Inhabitants. Future Internet (FIS'10). Lecture Notes in Computer Science 6369. DOI: http://doi.org/10.1007/978-3-642-15877-3_9.

[25] Scuri, S., et al. (2019). An HCI Perspective on Distributed Ledger Technologies for Peer-to-Peer Energy Trading. Human-Computer Interaction. Lecture Notes in Computer Science 11748. DOI: http://doi.org/10.1007/978-3-03029387-1_6.

[26] Singhal, A., and Saxena, R. (2012). Software models for smart grid. First International Workshop on Software Engineering Challenges for the Smart Grid. IEEE Press, pp. 42-45. DOI: https://doi.org/10.1109/SE4SG.2012.6225717.

[27] Srivatchan, N., and Rangarajan, P. (2020). A novel low-cost smart energy meter based on IoT for developing countries' micro grids. Concurrency Computat Pract Exper 32. DOI: https://doi.org/10.1002/cpe.5042.

[28] Strengers, Y., et al. (2020). Pursuing pleasance: Interrogating energy-intensive visions for the smart home. International Journal of Human-Computer Studies 136. DOI: https://doi.org/10.1016/j.ijhcs.2019.102379.

[29] Sun, X., et al. (2018). From HMI to HRI: Human-Vehicle Interaction Design for Smart Cockpit. Human-Computer Interaction. Lecture Notes in Computer Science 10902. DOI: https://doi.org/10.1007/978-3-319-91244-8_35.

[30] Urokohara, H., and Hirasawa, N. (2013) Managing HMI Quality in Embedded System Development. Human Interface and the Management of Information. Information and Interaction Design. Lecture Notes in Computer Science 8016. DOI: https://doi.org/10.1007/978-3-642-39209-2_17.

[31] Voinov, A. (2017), Automatic generation of function block systems implementing HMI for energy distribution automation. 2017 IEEE 15th International Conference on Industrial Informatics, Emden, pp. 706-713. DOI: https://doi.org/10.1109/INDIN.2017.8104859.

[32] Yesudas, R., and Clarke, R. (2015) Consumer Concerns About Smart Meters. Distributed, Ambient, and Pervasive Interactions (DAPI'15). Lecture Notes in Computer Science 9189. DOI: http://doi.org/10.1007/978-3-319-20804-6_57.

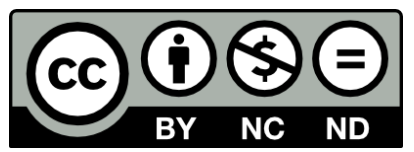

C 2020 by the authors. This work is licensed under the Creative Commons AttributionNonCommercial-NoDerivatives 4.0 International License. To view a copy of this license, visit http://creativecommons.org/licenses/by-nc-nd/4.0/ or send a letter to Creative Commons, PO Box 1866, Mountain View, CA 94042, USA. 